Silva, M.L., Perrier, L., Paget, W.J., Mosnier, A., Buthion, V., Cohen, J.M., Späth, H.M. Influenza vaccination policy-making processes in France and The Netherlands: framework and determinants. Health Policy: 2016, 120(3), 293-305

\begin{tabular}{|l|l|}
\hline $\begin{array}{l}\text { Postprint } \\
\text { Version }\end{array}$ & 1.0 \\
\hline $\begin{array}{l}\text { Journal website } \\
\text { Pubmed link }\end{array}$ & $\begin{array}{l}\text { 10.1016/j.healthpol.2016.01.005 } \\
\text { http://linkinghub.elsevier.com/retrieve/pii/S0168-8510(16)00006-3 }\end{array}$ \\
\hline DOI & http://www.ncbi.nlm.nih.gov/pubmed/26806677 \\
\hline
\end{tabular}

This is a NIVEL certified Post Print, more info at http://www.nivel.eu

\title{
Influenza vaccination policy-making processes in France and The Netherlands: Framework and determinants
}

\author{
MARIA LAURA SILVA ${ }^{\text {A, B, c, , , LIONEl PERRIER }}{ }^{\mathrm{A}, \mathrm{c}, \mathrm{D}}$, JOHN W. PAGET ${ }^{\mathrm{E}}$, ANNE MOSNIER $^{\mathrm{F}}$, \\ VALÉRIE BUTHION $^{\mathrm{A}, \mathrm{G}}$, JEAN MARIE COHEN ${ }^{\mathrm{F}}$, HANS MARTIN SPÄTH ${ }^{\mathrm{A}, \mathrm{H}}$ \\ ${ }^{a}$ University of Lyon, Lyon, France \\ ${ }^{\mathrm{b}}$ University of Bordeaux; Research Center Bordeaux Population HealthU1219 Inserm, \\ Bordeaux, France \\ ' University Lumière Lyon 2; CNRS, GATELSEUMR 5824, Ecully, France \\ d Direction of Clinical Research and Innovation, DRCl, Léon Bérard Cancer Centre, Lyon, \\ France \\ ${ }^{\text {e }}$ Netherlands Institute For Health Services Research (NIVEL), Utrecht, The Netherlands \\ ${ }^{f}$ Open Rome, Paris, France \\ ${ }^{9}$ University Lumière Lyon 2 COACTIS, EA 4161, Lyon, France \\ ${ }^{\mathrm{h}}$ University Claude Bernard Lyon 1, EAM 4128, Lyon, France
}

\begin{abstract}
Objectives: Target groups for seasonal influenza vaccination are nationally defined based on several factors. However, few studies have explored the policy-making processes at the country-level. We investigated key differences in the policy-making process for the development of vaccination recommendations between France (FR) and The Netherlands (NL). This paper presents preliminary results on the evidence used in the decision-making process and focuses on the interactions between the experts and stakeholders.

Methods: A documentary analysis identified the stakeholders of this process as governmental authorities, research institutions, associations, and manufacturers. This qualitative study included at least one expert from each stakeholder group. Thirty-three semi-structured interviews were performed in 2013 (16 FR, 17 NL). We used NVivo10® to perform a thematic content analysis on the data.

Results: National Immunization Technical Advisory Groups (NITAGs) were the key stakeholders in the development of recommendations. There was no systematic standard evaluation of evidence during the decision-making process in both countries. Likewise, voting was not systematic, although it did occur more often in FR. A declaration of interests was obligatory in both countries. Experts with no conflicts of interest were rare because many depend on private funding for their research on influenza vaccination.
\end{abstract}


Silva, M.L., Perrier, L., Paget, W.J., Mosnier, A., Buthion, V., Cohen, J.M., Späth, H.M. Influenza vaccination policy-making processes in France and The Netherlands: framework and determinants. Health Policy: 2016, 120(3), 293-305

Conclusions: The transparency of the NITAGs' procedures for the development of recommendations should be improved. We believe improvements might be achieved by the systematic standard evaluation of evidence, consistent voting, clear declarations of interest, and increased public funding for vaccination research.

\section{BACKGROUND}

A previous literature review of seasonal influenza vaccination identified three components of the policy-making process [1]: the decision-making process for vaccination recommendations, the implementation of these recommendations, and the funding of the vaccination. The recommendations for influenza vaccination mainly comprise indication of the target groups for free influenza vaccines, type of vaccines to use, and method of their administration. This component of the policymaking process is the principal interest of this paper because the vaccination recommendations serve as the basis for the development of the other components of the process (implementation and funding) [1].

In several countries, the development of recommendations is performed by independent advisory bodies, called National Immunization Technical Advisory Groups (NITAGs) [2], [3] and [4]. The NITAGs often use a systematic and transparent approach for increasing the quality and credibility of their advice, with the goal of contributing to its greater acceptance and broader implementation [5] and [6]. When developing vaccination recommendations, the NITAGs often refer to the international recommendations of the WHO and advice of supranational organisations, such as the ECDC (European Centre for Disease Prevention and Control) [7] and [8]. The ECDC website provides public access to vaccination policies, which can be compared between countries [9]. However, little is known about how NITAGs develop their national recommendations [1] and [10]. The complex interactions between the experts from the NITAGs and stakeholders involved in different levels of the policy-making process (e.g. international level: vaccine recommendations; national level: implementation and funding for influenza vaccinations) have been identified as one of the determinants for the development of national recommendations [8]. However, to the best our knowledge, the precise interactions between the experts and stakeholders and how they influence recommendations have not been investigated. For this type of analysis, qualitative methods could elucidate both the layperson's and professional's beliefs and explore their thoughts on this subject [11] and [12].

Only a few studies have investigated the seasonal, instead of pandemic, development of influenza recommendations outside of the United States [11], [13], [14] and [15]. France (FR) and The Netherlands (NL) are two countries within the European Union and WHO member states that have high seasonal influenza vaccination coverage rates (72\% NL, 52\% FR for elderly people $\geq 65$ years during the 2013-2014 season) [16] and [17]. Although their target groups for vaccination resemble other WHO member states, there are differences. For example, recommendations regarding pregnant women $(\mathrm{FR}=$ yes, $\mathrm{NL}=$ no) and the cut-off age for vaccination of the elderly (FR $\geq 65$ years, NL $\geq 60$ years) differ between the two countries [18] and [19]. We are interested in these countries because of their cultural differences, which could impact the development of recommendations and 
Silva, M.L., Perrier, L., Paget, W.J., Mosnier, A., Buthion, V., Cohen, J.M., Späth, H.M. Influenza vaccination policy-making processes in France and The Netherlands: framework and determinants. Health Policy: 2016, 120(3), 293-305

interactions between the experts and stakeholders [20], [21] and [22]. In addition, we have collaborations with French and Dutch research teams (see co-author affiliations).

We conducted a qualitative study in FR and NL to compare the key differences in the policy-making process of influenza vaccination. The objective of this project was:

(1) to propose a representation of the structure underlying the process, (2) to identify the interactions between the experts and stakeholders, and (3) to investigate the determinants for the development of vaccination recommendations. This paper focuses on the interactions between the experts from NITAGs and stakeholders of the national process and presents preliminary results on the use of evidence in policymaking processes.

\section{METHODS}

Two complementary techniques for data collection were used: (1) documentary analysis of the procedures, experts, and institutions (stakeholders) and (2) semistructured interviews to refine the data collected and provide in-depth investigation of the interactions among the experts and stakeholders. Each technique is described below.

\subsection{Documentary analysis}

The documentary analysis identified the stakeholders engaged in influenza policies in FR and NL, their position in their respective national health systems, and the experts directly and indirectly involved in the formulation of vaccination recommendations. We used a wide electronic search engine $\left(\right.$ Google $\left.{ }^{\circledR}\right)$ and entered keywords in English, French, and Dutch to search for hits regarding the health systems, influenza vaccination policies, and stakeholders. The search was limited to the last 10 years because policy procedures are constantly evolving, and older documents are probably obsolete. All stakeholder websites that were involved in policy processes were retained. The identified websites were carefully searched using the search strategy presented in Box 1 (additional online material). The documents were screened by two independent researchers based on their titles and abstracts. Documents were included in the study if they provided a description of: the flow of policy decisions, actors participating in counselling committees and advisory boards, and stakeholders supporting the process of vaccination recommendations.

\section{[BOX 1]}

\subsection{Interviews}

Based on the documentary analysis, we placed the stakeholders into four groups: governmental authorities, research institutions, associations, and manufacturers. For each stakeholder (institution/organisation), we identified the experts that were directly or indirectly involved in the development of vaccination recommendations (Table 1). At least one expert from each stakeholder group was approached for an anonymous interview, independent of their background and current job status. An invitation letter was sent by email or post; after two weeks, we phoned those who did not respond to the first invitation. If a face-to-face interview was not possible, we proposed a telephone interview. Some interviews were conducted with two or three people at the same time. 
Silva, M.L., Perrier, L., Paget, W.J., Mosnier, A., Buthion, V., Cohen, J.M., Späth, H.M. Influenza vaccination policy-making processes in France and The Netherlands: framework and determinants. Health Policy: 2016, 120(3), 293-305

\section{[TABLE 1]}

Based on a previous review [1], we developed a unique guide for the semi-structured interviews. It was composed in French and then translated into English; most of the Dutch experts were comfortable with an interview conducted in English. The guide focused on collecting the interviewees' perceptions about policy formulation and the transparency of the process, as well as the interactions between the experts directly and indirectly involved (Annexe 1). Both French and English guides were validated using pilot interviews with influenza experts in both countries. All three pilot interviews (two FR, one NL) were included in the analysis because they provided similar and relevant data; only minor modifications were made to the guide following these interviews.

One interviewer (MLS) conducted the 33 interviews (28 face-to-face and five telephone) in 2013: 16 in FR during the summer and 17 in NL during the autumn (Table 1). Each interview (mean length $59 \mathrm{~min}$ ) was audio recorded, under oral consent of the interviewee, and then transcribed.

The transcripts were analysed using thematic content analysis, where common themes are identified and grouped into codes. The codes constitute the unit of analysis and are derived from recurring patterns of speech and vocabulary [23]. A first coding scheme was manually developed through identifying verbatim in each transcript the answers that were relevant to the study questions. Transcripts were then coded with the same coding scheme using NVivo $10^{\circledR}$; when new ideas appeared, supplementary free codes were created. Points of difference between the first and second coding were solved by comparing the manual and electronic coding, and a final set of themes was developed. Finally, verbatim codings within all relevant themes were compared and analysed to identify the overall findings, as well as any differences in the interview responses across countries.

\subsection{Combining the data from the documents and interviews}

Combining the documents retrieved and the interview findings, we analysed the relationships between the experts inside the NITAGs and other stakeholders involved in the policy-making process for influenza vaccination recommendations in FR and NL. Schematic representations of the components of this process (development of vaccination recommendations, implementation, and funding) were developed and validated for each country.

\section{RESULTS}

The documents analysed generally consisted of official reports (e.g. the national recommendations for influenza vaccination published by the Health Councils), ministerial decrees (e.g. regarding the influenza immunisation program), scientific publications from influenza experts, and grey literature published on the websites of identified stakeholders (Annexe 2).

We obtained a response rate of $70 \%$ for the interviews; the non-responders were the healthcare insurance boards in both countries and the French medicines evaluation board (Table 1). Our sample was basically composed of governmental authorities (e.g. politicians, counsellors, and heads of departments), NITAG members, and employees of research institutions, with varied backgrounds (e.g. epidemiology, management, sociology, virology). Sixty percent declared that they were very experienced in the influenza domain. To respect the anonymity of the interviewees, we will not present further details because their identity would be easily recognised. 
Silva, M.L., Perrier, L., Paget, W.J., Mosnier, A., Buthion, V., Cohen, J.M., Späth, H.M. Influenza vaccination policy-making processes in France and The Netherlands: framework and determinants. Health Policy: 2016, 120(3), 293-305

In the following sections, we present the main results combined from the documentary analysis and interviews.

\subsection{Policy-making processes: Recommendations for influenza vaccination, implementation, and funding}

\subsubsection{The vaccination recommendations process}

\section{[FIGURE 1]}

In general, the Ministry of Health $(\mathrm{MoH})$ or the Health Directorate triggers the process by questioning their respective Health Council. This question is usually formally sent as a referral. Health Councils transfer the referral to a technical group or advisory board (commonly abbreviated as NITAG) that can appropriately deal with it. NITAGs are composed of experts (permanent or temporary members) who are responsible for selecting, categorising, and judging the evidence over several meetings. NITAGs answer each referral, which is formally written as a report, and send it to the Health Council. The Health Council provides a refined report to the Health Directorate who, together with the $\mathrm{MoH}$, analyses the advice provided. Afterwards, the $\mathrm{MoH}$ publishes the final decision.

Participants in FR and NL highlighted the important role of selecting the appropriate evidence for the development of recommendations. In NL, the secretariat of the Health Council (GR) was responsible for the collection and selection of evidence, which they then send to the NITAG. By contrast, in FR, these tasks are executed inside the CTV (French NITAG) by a small group of people who are nominated by the CTV chairman for each decision-making process. French and Dutch participants mentioned the existence of procedures for the evaluation of the selected evidence, but no standard procedure was systematically used.

National research institutes are the primary source of local evidence. Most of the experts that participate in NITAGs are attached to these research institutes. In NL, the RIVM (National Institute for Public Health and the Environment) was largely referred to as a key information provider. According to the participants, there were frequent requests for the RIVM to develop studies for the Dutch NITAG when local information was missing. Similarly, in FR, the InVS (Institute for Public Health Surveillance) was mentioned as the main source of epidemiological information. Other organisations also provide information but do not participate directly in the NITAGs, such as vaccine manufacturers and scientific associations (e.g. French Infectious Diseases Society [SPILF] and Dutch College of General Practitioners [NHG]).

Although the $\mathrm{MoH}$ is the final decision-maker, advice provided by the NITAGs is often considered, with minor modifications. Therefore, the NITAGs can be seen as the main stakeholder for the development of vaccination recommendations in both countries.

\subsubsection{The implementation of vaccination recommendations and funding}

\section{[FIGURE 2]}

Numerous stakeholders promote vaccination in FR (Fig. 2). Influenza vaccination recommendations are published in the "National Immunisation Schedule" (along with other recommended or mandatory vaccinations) by the $\mathrm{MoH}$. Recommendations 
Silva, M.L., Perrier, L., Paget, W.J., Mosnier, A., Buthion, V., Cohen, J.M., Späth, H.M. Influenza vaccination policy-making processes in France and The Netherlands: framework and determinants. Health Policy: 2016, 120(3), 293-305

are further published in medical newspapers and national colleges of healthcare professionals. In addition, an institute attached to the $\mathrm{MoH}$ and responsible for health education (French Institution for Prevention and Health Education [INPES]) publishes guides and advertisement materials for healthcare facilities/professionals, the general public, and target groups. Finally, the healthcare insurance board (CNAMTS) has a press conference (together with the MoH) to launch the vaccination campaign, posts newsletters to vaccinators, and sends vouchers to target groups.

By contrast, there is a single program in NL that manages influenza vaccinations (Fig. 2). The National Influenza Prevention Program (SNPG) is directly funded by the MoH and overseen by the RIVM. The SNPG uses an active approach with physicians, the main vaccinators. Physicians are encouraged to order vaccines through the SNPG website and invite their patients who are targeted for vaccination into the clinic. In addition, the NHG (Dutch College of General Practitioners) has a pro-active position and publishes guidelines for vaccination according to the national recommendations. These are sent directly to physicians.

FR and NL both provide free vaccines for target groups. There are financial incentives for the vaccinator in both countries, although there are different processes for vaccine purchases. Fig. 3 provides a representation of the interactions between the stakeholders involved in funding. We observed that in FR, there is another stakeholder (Economic Committee for Medicinal Products [CEPS]) involved in the process that does not exist in NL.

\section{[FIGURE 3]}

In FR, the price of the vaccine is negotiated between the CEPS (linked to both Ministries of Health and of Economy) and the manufacturer or distributor, once the vaccine is considered reimbursable by the Health Councils, HCSP/CTV (Technical Vaccination Committee), and HAS/CT (Transparency Committee) [24]. Currently, five brands of flu vaccines (from five manufacturers) are available in community pharmacies, which are responsible for their purchase. Pharmacies provide the vaccines without any charge to the target groups (through a voucher and/or prescription) and are further reimbursed by the CNAMTS. Target groups request vaccine administration by a physician or nurse who is reimbursed for the medical consultation (Fig. 3).

In NL, vaccine procurement is centralised by a national service for vaccine provision and prevention programs (DVP/RIVM). There is no price negotiation; instead, there is a European tender, whose requirements and conditions are publicly available.

Currently, there are two brands of flu vaccines (from two manufacturers) that best fit with the tender requirements: the first- and second-choice vaccine. Purchase from the latter is only done when there are shortages of the first-choice vaccine. The DVP works together with the SNPG to deliver the vaccines to physicians' offices. Physicians often invite target groups to receive a flu shot. They receive computer assistance, guidance for ordering the vaccines, and financial compensation for each person vaccinated. Expenses are covered by the SNPG, but vaccine waste over a certain percentage is charged to the physician (Fig. 3).

\subsection{Interactions between the experts in NITAGs and other stakeholders}

The relationship between the experts inside the NITAGs and their interaction with other stakeholders differed in FR and NL. These interactions and other 
Silva, M.L., Perrier, L., Paget, W.J., Mosnier, A., Buthion, V., Cohen, J.M., Späth, H.M. Influenza vaccination policy-making processes in France and The Netherlands: framework and determinants. Health Policy: 2016, 120(3), 293-305

characteristics of the NITAGs are further described below. Interviewees from both countries mentioned the influenza pandemic of 2009 as a trigger for changes in the NITAGs' policies; we used this example to illustrate the similarities and differences in the responses to these changes.

\subsubsection{Composition of the NITAGs}

The two countries have a similar size and composition of NITAGs (around 19 FR and $20 \mathrm{NL}$ ), which are composed of a chairman (and a vice-chairman in FR), members, observers, and secretaries (flexible in FR). In both countries, the Health Councils nominate the chairman/vice-chairman who then nominates the other board members. Several types of expertise are required, such as epidemiologists, immunologists, virologists, and clinicians, as well as others less linked to the disease, such as health-economists and ethicists. When expertise is missing, external experts from public or private institutes are temporarily invited to the board. Invited experts usually contribute to the discussions, notably with exhaustive explanations of coauthored studies, but they do not participate in the writing of the final recommendations.

\subsubsection{Evidence used during, length and conclusion of the discussion meetings}

In general, several meetings are necessary to put forth and evaluate the evidence. Sometimes these discussions are longer, depending on the availability and suitability of the evidence on the subject under discussion. The duration of this process, from the reception of the referral until the delivery of the final report, is slower in FR (612 months) than in NL (2-6 months). According to some French interviewees, before the influenza pandemic of 2009, the duration of the process was shorter because the process (described in Section 1.1) was less complex, had fewer steps, and had less people involved.

Participants in both countries equally emphasised the importance of the use of scientific evidence to support NITAG advice. The same evidence, mostly clinical/virological (e.g. vaccine efficacy/effectiveness, safety) and epidemiological studies (e.g. severity, morbidity, and mortality), were mentioned. These studies often come from similar international sources and are interpreted by the NITAGs during the meetings. However, in both countries, there were questions about the quality of the influenza studies and their applicability to national recommendations, although no systematic standard approach for grading and assessment of these studies was cited.

In both countries, the goal of the meetings is to reach a consensus by the end of the discussions. A few interviewees specified that voting was necessary when no consensus was achieved. In NL, voting is seen as a tendency for future meetings, where minor opinions can be stated in the final report. Several French interviewees mentioned that voting was a frequent practice but did not happen systematically. The writing of the final report is done by a writer and co-writer, who describe the discussions and evidence used to justify the advice. Most of the interviewees in both countries mentioned the importance of the writing: in NL, two fixed secretaries are in charge of the writing, whereas in FR, the chairman chooses one or two flexible members of the board to write the report. Only interviewees from NL stated that the report was publicly available in both Dutch and English. They emphasised that this 
Silva, M.L., Perrier, L., Paget, W.J., Mosnier, A., Buthion, V., Cohen, J.M., Späth, H.M. Influenza vaccination policy-making processes in France and The Netherlands: framework and determinants. Health Policy: 2016, 120(3), 293-305

publication was an important way to show the independence of the advice provided by the NITAG.

\subsubsection{Relationship between the experts inside the NITAGs}

The majority of interviewees declared that the influenza domain is small and experts had knowledge about each other's work. Therefore, there was a pleasant atmosphere during the meetings. However, some interviewees mentioned that this scenario could be strained when experts with a stronger personality, named 'vocal-people', expressed their opinion in a more enthusiastic manner.

Interviewees had different opinions about 'vocal-people'. Most Dutch interviewees mentioned that experts were eager to express their opinion as part of the scientific debate. Indeed, some interviewees indicated that people were reasonably reliable, wanted to cooperate with each other, and their relationship was based on trust. By contrast, French interviewees mostly stated that 'vocal-people' could influence others in the NITAG, and they perceived this influence as a negative factor for discussions, where the opinions of experts with more subdued personalities could be distorted or ignored. Therefore, the role of the French chairman was emphasised as extremely important to avoid conflicts and enable equilibrium for the discussions. In both countries, experts have their fees reimbursed for participating in the NITAG. In addition, Dutch experts received financial incentives for their participation. In FR, several interviewees complained about the unsatisfactory situation regarding the slowness of the reimbursement system.

Some interviewees, especially in FR, mentioned that the lack of public incentives increased the private funding of experts' research projects (e.g. coming from the pharmaceutical industry), which decreased the independence of the experts and could influence their advice.

\subsubsection{Determinants for participation in the discussion meetings}

There are different levels of participation in the meetings. The specific conditions for participation are not clearly stated, but only permanent members have the right to vote and participate in the development of the reports; invited experts only provide information under chapters named "experts' advice". Interviewees also mentioned that their "right to vote" was related to their involvement with other stakeholders, for example, the Health Directorate or the MoH (any direct relationship with the final decision-makers prevented voting).

Many interviewees mentioned conflicts of interest that could affect the experts' independence because of their close relationship (lay or professional) with private companies. In NL, several interviewees mentioned that specific conflicts of interest with regards to a specific topic under discussion disabled the participation of the expert in the NITAG (e.g. if the topic under discussion was 'should healthy children be included in target groups', the expert could not be involved with research on 'vaccinating healthy children'). One Dutch interviewee also declared the possibility of 'unconscious influence' from private companies. French interviewees also mentioned that participation as a permanent member in the committee required that the expert must be free of conflicts of interest.

In both countries, interviewees mentioned the difficulty in staying completely disconnected from private companies. Others mentioned that, despite the proximity of the private companies, experts were scientifically independent because they 
Silva, M.L., Perrier, L., Paget, W.J., Mosnier, A., Buthion, V., Cohen, J.M., Späth, H.M. Influenza vaccination policy-making processes in France and The Netherlands: framework and determinants. Health Policy: 2016, 120(3), 293-305

worked under contract with these companies and when these contracts were over, there were no longer direct links. In NL, more facts related to the independence of experts were mentioned. However, in both countries, there was a unanimous enthusiasm for improving experts' independence using the declaration of interests, which became stricter after the pandemic episode of 2009: before each decision meeting, experts are obliged to provide a public statement of any conflicts of interest or the avoidance of links. People in charge of the organisation of each meeting determine the level of participation in the board (e.g. right to vote or only take part in the discussions). Some French interviewees mentioned that this was a highly individual judgment based on no objective criteria.

After the pandemic episode of 2009, both French and Dutch NITAGs were reformed, adopting stricter rules regarding the experts' relationships with private industry and requiring declarations of interest. Several permanent members became 'invited experts' because of their close relationship with private companies or other stakeholders. People with less experience in influenza vaccination replaced older members. Interviewees had different perceptions of these changes: while some believed that new people with new strategies would improve the transparency of the process (e.g. more independent and more objective decisions), others thought that the process would become mechanistic (e.g. naive grading and evaluation of the evidence to build a decision), without the real-life opinions of experienced people.

\section{DISCUSSION}

The outcomes presented here contribute to the existing literature about the policymaking process of influenza vaccination. Based on our findings, we were able to identify the interactions between the experts and stakeholders involved in this process. We developed an original schematic framework of this process, which may help policy-makers and researchers develop a holistic perspective that could be used to improve the process. However, further investigation, for instance based on observational studies, is necessary to clarify 'how' the development of recommendations is made in the real world. Using the results presented here and in the literature [22], [25], [26], [27] and [28], we have proposed some hypotheses about the determinants of the policy-making process, which may be helpful for policy-makers searching for improvements.

\subsection{Framework of the policy-making process}

FR and NL have well-established structures for their influenza vaccination policies, although the experts involved have different roles and interactions. To analyse these differences, we developed schematic flowcharts of the decision-making process for the vaccination recommendations (Fig. 1) and the implementation of these recommendations (Fig. 2). We highlighted two main differences between FR and NL: (1) while actions are nationally centralised in NL through the RIVM, in FR, there are numerous stakeholders and (2) while in FR there are no formal links between vaccinators and other stakeholders, in NL, the vaccinators have an active interaction with other stakeholders and vice versa.

We believe that the nationally centralised Dutch influenza program (SNPG/RIVM) could be one of the determinants of the higher vaccination rates in NL. The SNPG facilitates the implementation of vaccination recommendations, has strong links with stakeholders, and promotes excellent assimilation (by vaccinators) of the specifications of the recommendations [29] and [30]. Many papers have shown the 
Silva, M.L., Perrier, L., Paget, W.J., Mosnier, A., Buthion, V., Cohen, J.M., Späth, H.M. Influenza vaccination policy-making processes in France and The Netherlands: framework and determinants. Health Policy: 2016, 120(3), 293-305

positive impact that vaccinators, especially general practitioners, have on influenza vaccination rates [31], [32], [33], [34] and [35].

Financial incentives for Dutch vaccinators may also contribute to their higher vaccination rates [36] and [37], although French general practitioners may also receive extra payment for the achievement of pre-established goals on vaccination of target groups (pay-for-performance [38]). Nevertheless, the involvement of the vaccinators in the policy-making process should be emphasised to improve their engagement in passing on the recommendations [39].

\subsection{Determinants for the development of national vaccination recommendations}

\subsubsection{Evaluation of the evidence}

The NITAGs from both countries used similar evidence. However, the uncertainty about the quality and relevance of the evidence used for the influenza vaccination recommendations meant that the experts' interpretation was of utmost importance in the process.

The use of the GRADE approach (Grading of Recommendations Assessment, Development, and Evaluation) has been widely discussed in recent publications (notably in immunisation policy) [28], [40] and [41]. This approach follows three main steps: the appraisal of the quality of evidence, the judgment between desirable and undesirable effects, and the choice of recommendation strength [42] and [43]. The ability to make considered decisions based on the quality of the evidence independent of coming to sensible conclusions about the strength of the recommendations is a critical and defining feature [28]. Therefore, we believe that the GRADE approach is an important tool that could be systematically used as a standard procedure in both countries to minimise the personal influence of experts and improve the quality and transparency of the decision-making process in FR and NL [5], [44] and [45].

\subsubsection{Voting and NITAG coordination}

In contrast to the existing literature, we found that voting in the NITAGs did not happen systematically at the end of meetings. Instead, a consensus is often preferred, notably in NL [18], [46] and [47]. Since voting is a democratic method to obtain a fair decision, NITAGs could prioritise this to improve transparency. As emphasised in the literature, this simple method enables the quantitative reporting of pro and con votes and the description of minor disagreements. In addition, experts with a minority opinion can declare their opposition to the advice given [18], [46] and [47]. French interviewees criticised the lack of objective arguments concerning the right to vote and the selection of the writer/co-writer of the report. Improving the confidence between the experts inside the advisory boards could decrease any disagreements that occur (e.g. chairmen, report writers, and invited experts). Confidence could be enhanced by providing a clear definition of the roles of the permanent and invited members and using standard criteria for the right to vote and for the participation in the report writing.

\subsubsection{Declaration of interests}

The right to vote depends on the experts' declaration of interests. As in most countries where vaccination recommendations are developed by NITAGs [18], 
Silva, M.L., Perrier, L., Paget, W.J., Mosnier, A., Buthion, V., Cohen, J.M., Späth, H.M. Influenza/ vaccination policy-making processes in France and The Netherlands: framework and determinants. Health Policy: 2016, 120(3), 293-305

[46] and [47], the public declaration of interests is obligatory for permanent and invited members of the boards [48], [49], [50] and [51]. However, the participants in our survey admitted that it is almost impossible to avoid links with private companies in the influenza scientific and medical communities, which may impede the experts' right to vote, notably in FR [18].

\subsubsection{Public funding and independence of the experts}

The scarcity of influenza experts with enough expertise to participate in the NITAGs is evident in both countries. In general, experts are involved in influenza vaccination research, which lacks any substantial public investments. This absence of public incentives has necessitated private funding from the pharmaceutical industry, which notably invests in new vaccine technology research or epidemiological follow-ups of laboratory-confirmed influenza cases. Therefore, the involvement of experts with the private sector, especially influenza vaccine manufacturers, is currently inevitable. These links with vaccine manufacturers are historical. In the past, national governments, especially in FR (Sanofi Pasteur) and NL (National Vaccine Institute), had their own non-profit local production and distribution of influenza vaccines. In that time, there were less issues with conflicts of interest because the 'government bought from the government' [52]. However, in our now globalised world, these national companies could not afford the high costs of rigorous production processes and were incorporated into multinational, profit-oriented manufacturers. Therefore, governmental authorities must now interact with multinational manufacturers or distributors of influenza vaccines. These companies have large funds to develop studies for their products, which are often done in partnership with the public sector [52].

\subsection{Limitations}

The decision-making process for the development of influenza vaccination recommendations by NITAGs is complex. The results presented here could not elucidate the exact development of recommendations. Indeed, we believe that the inscrutability of the process may evoke suspicions about its transparency.

All of the participants in this study were attached to the healthcare system: $60 \%$ were very experienced with influenza vaccination recommendations and focused on the internal aspects of the NITAG meetings; $40 \%$ were less experienced and provided a holistic view of the other components of the policy-making process (e.g. implementation and funding of vaccinations). However, the views of individuals outside the healthcare system were not represented, notably people who are against vaccination. Although this suits the objectives of this study, our findings do not represent this perspective.

The CNAMTS and CVZ (the French and Dutch Healthcare Insurance Boards, respectively) indicated that they were not interested in being interviewed. These organisations execute decisions from the MoH; the CNAMTS is responsible for funding the influenza vaccination policies, although the CVZ is not. The perspective of the CNAMTS would have enriched our outcomes because funding is of utmost importance for implementing the program and may influence the development of recommendations. We were disappointed by the refusal of the French health insurance to accommodate our request and recommend further attempts to obtain their viewpoint about the funding process to contrast with the presented outcomes. In addition, the French Medicines Evaluation Board (ANSM), which is responsible for 
Silva, M.L., Perrier, L., Paget, W.J., Mosnier, A., Buthion, V., Cohen, J.M., Späth, H.M. Influenza vaccination policy-making processes in France and The Netherlands: framework and determinants. Health Policy: 2016, 120(3), 293-305

influenza vaccine authorisation, did not contribute to our study. This absence could have biased our French results, although experts from other stakeholders provided significant information covering these missing data.

We have only used two methodological techniques to conduct this project: documentary analysis and interviews. The triangulation of these two techniques plus an observational study, for instance, would have enabled a real-world analysis [12]. Although we thought about adding this third technique (the on-site observation of the decision-making process), it has not yet been undertaken. We were afraid that access to the committee meetings in FR and NL would be denied, and direct observation would not be possible. However, there are limitations to this type of data. The potential subjective bias on the part of the observer could have undermined the reliability of the results and the validity of the data gathered. In addition, the observations of the numerous stakeholders identified would simply not be feasible because of limited time and resources.

Our approach to the interviews could produce a declaration bias, where the discourse on a given theme could remain superficial (under-declaration) or excessively intense (over-declaration). We found two instances of this in our study: the under-declaration of the financing of the vaccination programs in both countries, especially in FR, and the over-declaration from French interviewees about personal judgments regarding the conflicts of interest, claiming it was a barrier for participation in the expert committees. Another possible limitation is recall bias; however, this was not relevant to our study because participants were interviewed during or a few weeks after the discussions regarding the update of vaccination recommendations. Finally, affiliation bias was not relevant to our study because our main research group was not associated with the policy-making process.

Language barriers are another limitation of our study: the interviews were carried out and analysed by a sole investigator who did not speak Dutch. We are aware of the issues of accuracy with online translations of Dutch documents; therefore, a Dutch influenza expert validated the data reported in this paper.

Although NVivo $10^{\circledR}$ was used to validate the coding of themes, there could have been errors regarding the relevance of the information retained in each of the transcripts analysed. This main limitation of this software could have led to under- or over-estimation of the importance of the citations.

\section{CONCLUSIONS}

We believe that the implementation of vaccination recommendations could be improved by stronger links between the vaccinators and governmental authorities. Further investigation is underway to evaluate the opinion of general practitioners about which incentives are necessary to improve vaccination rates of target groups. To better understand 'how' national recommendations are developed, we believe that the process must be made more transparent. We think that improvements could be achieved with the following important determinants: the systematic standard evaluation of evidence (e.g. GRADE approach), consistent voting, clear declaration of interests, and increased public funding for vaccination research. Further investigations based on observational studies of these determinants should be done to confirm their impact on the transparency and understanding of the policy-making process. 
Silva, M.L., Perrier, L., Paget, W.J., Mosnier, A., Buthion, V., Cohen, J.M., Späth, H.M. Influenza/ vaccination policy-making processes in France and The Netherlands: framework and determinants. Health Policy: 2016, 120(3), 293-305

\section{Competing interests}

The authors declare that they have no competing interests.

\section{Author contributions}

HMS, JP, AM, and VB designed the survey strategy. MLS performed the documentary analysis, interviews, transcription, and coding. HMS, JP, AM, VB, LP, and MLS participated in the data analysis. HMS, JP, AM, VB, LP, MLS, and JMC prepared the manuscript. All of the authors read and approved the final manuscript.

\section{Acknowledgments}

MLS received a doctoral scholarship from the Science without Borders program, primarily funded by the Brazilian Federal Government. The authors would like to thank the interviewees for their availability and helpful discussions. We are grateful to the participants of the NIVEL WO of 19/03/2015 for their detailed review and insightful comments. We thank Joost Timmermans from the RIVM and François Schellevis, Madelon Kroneman, Mariette Hooiveld, and Ge Donker from the NIVEL for their help with the Dutch health system and influenza vaccination policy. Sophie Domingues-Montanari helped with the final editing of the manuscript.

\section{Appendix A. Supplementary data}

\section{REFERENCES}

[1] M.L. Silva, L. Perrier, J.M. Cohen, W.J. Paget, A. Mosnier, H.M. Späth A literature review to identify factors that determine policies for influenza vaccination Health Policy, 119 (2015), pp. 697-708 http://dx.doi.org.proxy.library.uu.nl/10.1016/j.healthpol.2015.04.006 [2] P. Duclos, S. Ortynsky, N. Abeysinghe, N. Cakmak, C.B. Janusz, B. Jauregui, et al. Monitoring of progress in the establishment and strengthening of national immunization technical advisory groups Vaccine, 30 (2012), pp. 7147-7152 http://dx.doi.org.proxy.library.uu.nl/10.1016/j.vaccine.2012.04.015

[3] P. Duclos, J.-M. Okwo-Bele, D. Salisbury Establishing global policy recommendations: the role of the Strategic Advisory Group of Experts on immunization Expert Review of Vaccines, 10 (2011), pp. 163-173 http://dx.doi.org.proxy.library.uu.nl/10.1586/erv.10.171

[4] B.D. Gessner, P. Duclos, D. DeRoeck, E.A.S. Nelson Informing decision makers: experience and process of 15 National Immunization Technical Advisory Groups Vaccine, 28 (Suppl. 1) (2010), pp. A1-A5 http://dx.doi.org.proxy.library.uu.nl/10.1016/j.vaccine.2010.02.025

[5] D. Matysiak-Klose, F. Ahmed, P. Duclos, Y. Falck-Ytter, F. Forland, H. Houweling, et al. Report on the 1st international workshop on procedures for the development of evidencebased vaccination recommendations, Berlin, Germany, 22-23 November 2010 Vaccine, 30 (2012), pp. 2399-2404 http://dx.doi.org.proxy.library.uu.nl/10.1016/j.vaccine.2011.12.004

[6] NITAG Resource Center Supporting evidence-informed decision making for immunization programs and policies OMS-NiTAGS Ressour Cent (2015) http://www.url_of_what_is_shared_or_liked.com (accessed April 9, 2015)

[7] H. Nohynek, O. Wichmann, F. D'Ancona National Advisory Groups and their role in immunization policy-making processes in European countries Clinical Microbiology and Infection, 19 (2013), pp. 1096-1105 http://dx.doi.org.proxy.library.uu.nl/10.1111/14690691.12315

[8] P. Saliou, J. Blau, K. Senouci Du Programme élargi de vaccination (PEV) aux Programmes nationaux de vaccination (PNV): intérêt des groupes techniques consultatifs pour la vaccination (GTCV) Bulletin de la Société de Pathologie Exotique, 105 (2012), pp. 311-314 http://dx.doi.org.proxy.library.uu.nl/10.1007/s13149-012-0245-x

[9] European Centre for Disease Prevention and Control Vaccine schedule ECDC (2015) http://vaccine-schedule.ecdc.europa.eu.proxy.library.uu.nl/Pages/Scheduler.aspx (accessed August 11, 2015) 
Silva, M.L., Perrier, L., Paget, W.J., Mosnier, A., Buthion, V., Cohen, J.M., Späth, H.M. Influenza vaccination policy-making processes in France and The Netherlands: framework and determinants. Health Policy: 2016, 120(3), 293-305

[10] G.W. Ricciardi, M. Toumi, C. Weil-Olivier, E.J. Ruitenberg, D. Dankó, G. Duru, et al. Comparison of NITAG policies and working processes in selected developed countries Vaccine, 33 (2015), pp. 3-11 http://dx.doi.org.proxy.library.uu.nl/10.1016/j.vaccine.2014.09.023

[11] L.C. Rosella, K. Wilson, N.S. Crowcroft, A. Chu, R. Upshur, D. Willison, et al. Pan demic $\mathrm{H} 1 \mathrm{~N} 1$ in Canada and the use of evidence in developing public health policies-a policy analysis Social Science \& Medicine, 83 (2013), pp. 1-9 http://dx.doi.org.proxy.library.uu.nl/10.1016/j.socscimed.2013.02.009 1982

[12] C. Pope, N. Mays Qualitative research in health care Wiley (2008) http://books.google.fr/books?id=G7OhOS2XrVYC

[13] T. Timpka, H. Eriksson, E.A. Gursky, J.M. Nyce, M. Morin, J. Jenvald, et al. Populationbased simulations of influenza pandemics: validity and significance for public health policy Bulletin of the World Health Organization, 87 (2009), pp. 305-311 http://dx.doi.org.proxy.library.uu.nl/10.1590/S0042-96862009000400016

[14] A. Schuchat, B.P. Bell, S.C. Redd The science behind preparing and responding to pandemic influenza: the lessons and limits of science Clinical Infectious Diseases, 52 (2011), pp. S8-S12

[15] J.P. Garoon, P.S. Duggan Discourses of disease, discourses of disadvantage: a critical analysis of National Pandemic Influenza Preparedness Plans Social Science \& Medicine, 67 (2008), pp. 1133-1142 http://dx.doi.org.proxy.library.uu.nl/10.1016/j.socscimed.2008.06.0201982

[16] M.A.J.B. Tacken, B. Jansen, J. Mulder, W. Tiersma, J.C.C. Braspenning Monitoring vaccination rate Dutch national influenza prevention program 2013 RIVM (2014) http://www.rivm.nl/dsresource?objectid=rivmp:260408\&type=org\&disposition=inline (accessed January 8, 2015)

[17] INVS, Couverture vaccinale grippe par saison et dans chaque groupe d'âge (CNAMTS) Données Par Groupe D'âge Couverture Vaccinale Grippe Institut de Veille Sanitaire (2015) 〈http://www.invs.sante.fr/Dossiers-thematiques/Maladies-infectieuses/Maladies-aprevention-vaccinale/Couverture-vaccinale/Donnees/Grippe〉 (accessed January 8, 2015)

[18] D. Floret Vaccinations: élaboration des recommandations et de leur évolution en France Annales Pharmaceutiques Françaises, 67 (2009), pp. 219-223 http://dx.doi.org.proxy.library.uu.nl/10.1016/j.pharma.2009.03.006

[19] H. Houweling, M. Verweij, E.J. Ruitenberg Criteria for inclusion of vaccinations in public programmes Vaccine, 28 (2010), pp. 2924-2931 http://dx.doi.org.proxy.library.uu.nl/10.1016/j.vaccine.2010.02.021

[20] N. Belhoste, P. Monin Constructing differences in a cross-cultural context: national distance, social differentiation or functional distinction Human Relations, 66 (2013), pp. 1529-1561 http://dx.doi.org.proxy.library.uu.nl/10.1177/0018726713484943

[21]W.J.M. Kickert Public Governance in the Netherlands: an alternative to Anglo-American managerialism Public Administration, 75 (1997), pp. 731-752 http://dx.doi.org.proxy.library.uu.nl/10.1111/1467-9299.00084

[22] O. Belkhodja Knowledge utilization in canadian health service organizations: a path analysis International Journal of Public Administration, 37 (2014), pp. 339-352 http://dx.doi.org.proxy.library.uu.nl/10.1080/01900692.2013.837070

[23] S. Ozawa, L.A. Privor-Dumm, A. Nanni, E. Durden, B.A. Maiese, C.U. Nwankwo, et al. Evidence-to-policy gap on hepatitis A vaccine adoption in 6 countries: literature vs policymakers' beliefs

Vaccine, 32 (2014), pp. 4089-4096 http://dx.doi.org.proxy.library.uu.nl/10.1016/j.vaccine.2014.05.026

[24] D. Floret, P. Deutsch The French Technical Vaccination Committee (CTV) Vaccine, 28 (Suppl. 1) (2010), pp. A42-A47 http://dx.doi.org.proxy.library.uu.nl/10.1016/j.vaccine.2010.02.032

[25] S. Ettelt, N. Mays, P. Allen

Policy experiments: investigating effectiveness or confirming direction? Evaluation, 21 (2015), pp. 292-307 ttp://dx.doi.org.proxy.library.uu.nl/10.1177/1356389015590737 
Silva, M.L., Perrier, L., Paget, W.J., Mosnier, A., Buthion, V., Cohen, J.M., Späth, H.M. Influenza/ vaccination policy-making processes in France and The Netherlands: framework and determinants. Health Policy: 2016, 120(3), 293-305

[26] T. Greenhalgh, J. Russell Reframing evidence synthesis as rhetorical action in the policy making drama Healthcare policy / Politiques de santé, 1 (2006), pp. 34-42 ISSN: 17156572 (Print)

[27] R. Hulme, M. Hulme Policy learning? Crisis, evidence and reinvention in the making of public policy Policy \& Politics, 40 (2012), pp. 473-489 http://dx.doi.org.proxy.library.uu.nl/10.1332/030557312X645757

[28] F. Ahmed, J.L. Temte, D. Campos-Outcalt, H.J. Schünemann Methods for developing evidence-based recommendations by the Advisory Committee on Immunization Practices (ACIP) of the U.S. Centers for Disease Control and Prevention (CDC) Vaccine, 29 (2011), pp. 9171-9176 http://dx.doi.org.proxy.library.uu.nl/10.1016/j.vaccine.2011.08.005

[29] L. Privileggio, A. Falchi, M.-L. Grisoni, C. Souty, C. Turbelin, L. Fonteneau, et al. Rates of immunization against pandemic and seasonal influenza in persons at high risk of severe influenza illness: a cross-sectional study among patients of the French Sentinelles general practitioners BMC Public Health, 13 (2013), p. 246 http://dx.doi.org.proxy.library.uu.nl/10.1186/1471-2458-13-246

[30] L. van Ruiten, P.L. Lopalco, J. Ruitenberg Challenges in national immunisation programmes: a policy perspective from Austria, the Netherlands and the United Kingdom European Centre for Disease Prevention and Control, Stockholm, Sweden (2013)

[31] H. Schmitz, A. Wubker What determines influenza vaccination take-up of elderly Europeans? Health Economics, 20 (2011), pp. 1281-1297 http://dx.doi.org.proxy.library.uu.nl/10.1002/\%28ISSN\%291099-1050/issues

[32] I. Looijmans-van den Akker, M.E. Hulscher, T.J. Verheij, J. Riphagen-Dalhuisen, J.J. van Delden, E. Hak How to develop a program to increase influenza vaccine uptake among workers in health care settings? Implementation Science IS, 6 (2011), p. 47 http://dx.doi.org.proxy.library.uu.nl/10.1186/1748-5908-6-47

[33] J. Riphagen-Dalhuisen, J.C.F. Kuiphuis, A.R. Procé, W. Luytjes, M.J. Postma, E. Hak Contributing factors to influenza vaccine uptake in general hospitals: an explorative management questionnaire study from the Netherlands BMC Public Health, 12 (2012), p. $1101 \mathrm{http}: / / \mathrm{dx}$.doi.org.proxy.library.uu.nl/10.1186/1471-2458-12-1101

[34] C.E. Hopman, J. Riphagen-Dalhuisen, I. Looijmans-van den Akker, G. Frijstein, A.D.J. Van der Geest-Blankert, M.B. Danhof-Pont, et al. Determination of factors required to increase uptake of influenza vaccination among hospital-based healthcare workers Journal of Hospital Infection, 77 (2011), pp. 327-331 http://dx.doi.org.proxy.library.uu.nl/10.1016/j.jhin.2010.10.009

[35] A. While, C. George, B. Murgatroyd Promoting influenza vaccination in older people: rationale and reality British Journal of Community Nursing, 10 (2005), pp. 427-430

[36] R.W. Kouides, N.M. Bennett, B. Lewis, J.D. Cappuccio, W.H. Barker, F.M. LaForce, et al. Performance-based physician reimbursement and influenza immunization rates in the elderly American Journal of Preventive Medicine, 14 (1998), pp. 89-95 http://dx.doi.org.proxy.library.uu.nl/10.1016/S0749-3797(97)00028-7

[37] M. Kroneman, G.A. van Essen, W. John Paget Influenza vaccination coverage and reasons to refrain among high-risk persons in four European countries Vaccine, 24 (2006), pp. 622-628 http://dx.doi.org.proxy.library.uu.nl/10.1016/j.vaccine.2005.08.040

[38] Assurance Maladie, Rémunération sur objectifs de santé publique

Assurance Maladie / French Health Insurance (2014)

http://www.ameli.fr.proxy.library.uu.nl/professionnels-de-sante/medecins/votreconvention/remuneration-sur-objectifs-de-sante-publique.php〉 (accessed December 10, 2014)

[39] D. Anantham, W. McHugh, S. O'Neill, L. Forrow Clinical review: influenza pandemicphysicians and their obligations Critical Care, 12 (2008), pp. 1-5 http://dx.doi.org.proxy.library.uu.nl/10.1186/cc6918

[40] G. Samaan, M. McPherson, J. Partridge A review of the evidence to support influenza vaccine introduction in countries and areas of WHO's Western Pacific Region PLoS ONE, 8 (2013), p. e70003 http://dx.doi.org.proxy.library.uu.nl/10.1371/journal.pone.0070003

[41] F. Ahmed, M.C. Lindley, N. Allred, C.M. Weinbaum, L. Grohskopf Effect of influenza vaccination of healthcare personnel on morbidity and mortality among patients: systematic review and grading of evidence Clinical Infectious Diseases, 58 (2014), pp. 50-57 http://dx.doi.org.proxy.library.uu.nl/10.1093/cid/cit580 
Silva, M.L., Perrier, L., Paget, W.J., Mosnier, A., Buthion, V., Cohen, J.M., Späth, H.M. Influenza/ vaccination policy-making processes in France and The Netherlands: framework and determinants. Health Policy: 2016, 120(3), 293-305

[42] G.H. Guyatt, A.D. Oxman, G.E. Vist, R. Kunz, Y. Falck-Ytter, P. Alonso-Coello, et al. GRADE: an emerging consensus on rating quality of evidence and strength of recommendations British Medical Journal, 336 (2008), pp. 924-926 http://dx.doi.org.proxy.library.uu.nl/10.1136/bmj.39489.470347.AD

[43] G.H. Guyatt, A.D. Oxman, R. Kunz, G.E. Vist, Y. Falck-Ytter, H.J. Schünemann, et al. What is quality of evidence and why is it important to clinicians? British Medical Journal, 336 (2008), pp. 995-998 http://dx.doi.org.proxy.library.uu.nl/10.1136/bmj.39490.551019.BE

[44] G.H. Guyatt, A.D. Oxman, R. Kunz, Y. Falck-Ytter, G.E. Vist, A. Liberati, et al. Going from evidence to recommendations

British Medical Journal, 336 (2008), pp. 1049-1051

http://dx.doi.org.proxy.library.uu.nl/10.1136/bmj.39493.646875.AE

[45] D. Atkins, D. Best, P.A. Briss, M. Eccles, Y. Falck-Ytter, S. Flottorp, et al. Grading quality of evidence and strength of recommendations British Medical Journal, 328 (2004), p. $1490 \mathrm{http}: / / \mathrm{dx}$.doi.org.proxy.library.uu.nl/10.1136/bmj.328.7454.1490

[46] M. Bryson, P. Duclos, A. Jolly, J. Bryson A systematic review of national immunization policy making processes

Vaccine, 28 (Suppl. 1) (2010), pp. A6-A12 http://dx.doi.org.proxy.library.uu.nl/10.1016/j.vaccine.2010.02.026

[47] J.C. Smith The structure, role, and procedures of the U.S. Advisory Committee on Immunization Practices (ACIP) Vaccine, 28 (Suppl. 1) (2010), pp. A68-A75 http://dx.doi.org.proxy.library.uu.nl/10.1016/j.vaccine.2010.02.037

[48] République française LOI no 98-535 du 1er juillet 1998 relative au renforcement de la veille sanitaire et du contrôle de la sécurité sanitaire des produits destinés à l'homme République française (1998)

[49] République française LOI no 2002-303 du 4 mars 2002 relative aux droits des malades et à la qualité du système de santé République française (2002)

[50] République française Loi no 93-122 du 29 janvier 1993 relative à la prévention de la corruption et à la transparence de la vie économique et des procédures publiques République française (1993)

[51]S.M. Bartman Report from the Netherlands European and Company Law, 3 (2006), pp. 33-34

[52] P.P. Berman, W.A. Orenstein, A.R. Hinman, J. Gazmararian

Stakeholder attitudes toward influenza vaccination policy in the United States Health Promotion Practice, 11 (2010), pp. 807-816

\section{TABLES AND FIGURES}

Box 1 Strategy for online database searches, keywords (English, French, and Dutch), and main sources of material obtained for France and The Netherlands

(i) demographics and socio-economic context

Keywords (similar for both countries):

health, Gross Domestic Product (GDP), indicators, economy

Websites (similar for both countries):

OECD (http://data.oecd.org/gdp/gross-domestic-product-gdp.htm),

WHO (http://data.euro.who.int/healthatlas/CorelndicatorAP/corenotes.htm)

(ii) health systems

Kerwords:

Système de santé, réforme, France

Gezondheidszorg, hervorming, Nederland

Websites (similar for both countries):

European Observatory on Health Systems and Policie

(http://www.euro.who.int/en/about-us/partners/observatory)

http://www.cairn.info/revue-les-tribunes-de-la-sante.htm

(iii) influenza vaccination policies and (iv) stakeholders involved in policies

Keywords Grippe, vaccination, vaccin, remboursement,

Griep, influenza, vaccinatie, vaccin, vergoeden, stratégie vaccinale, recommandation, avis, vaccinatiestrategie, rapport, advise, rapport, conseil

Websites

Ministries of health

http://www.sante.gouv.fr

http://www.hcsp.fr/explore.cg

recommandatie

Governmental authorities

http://www.has-sante.fr

http://www.rijksoverheid.nl/ministeries/vws

http://www.has-san

http://www.gezondheidsraad.nl

http://www.ameli.fr

Laboratories, Surveillance networks

http://grog.org

http://www.invs.sante.fr

http://www.cbg-meb_nl/cbg/nl

http://www.zorginstituutnederland.n

http://www.rivm.nl

http://www.nivel.n

http://www.snpg.n

Associations

http://www. Infectiologie.com

https://www.nhg.org

Dutch websites were automatically translated to English using the Chrome ${ }^{\circledR}$ browser. 
Silva, M.L., Perrier, L., Paget, W.J., Mosnier, A., Buthion, V., Cohen, J.M., Späth, H.M. Influenza/ vaccination policy-making processes in France and The Netherlands: framework and determinants. Health Policy: 2016, 120(3), 293-305

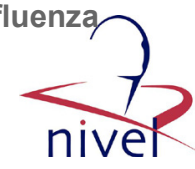

Table 1

Stakeholders directly or indirectly involved in the decision-making process of influenza vaccination recommendations in France and The Netherlands.

\begin{tabular}{|c|c|c|c|c|c|c|c|}
\hline \multirow{3}{*}{$\begin{array}{l}\text { Groups of } \\
\text { stake-holders }\end{array}$} & \multirow[t]{3}{*}{ Stakeholder } & \multicolumn{3}{|l|}{ France } & \multicolumn{3}{|c|}{ The Netherlands } \\
\hline & & \multirow{2}{*}{$\begin{array}{l}\text { Stake- } \\
\text { holder } \\
\text { acronym }\end{array}$} & \multicolumn{2}{|c|}{ Experts interviewed } & \multirow{2}{*}{$\begin{array}{l}\text { Stake- } \\
\text { holder } \\
\text { acronym }\end{array}$} & \multicolumn{2}{|c|}{ Experts interviewed } \\
\hline & & & ID & $\begin{array}{l}\text { Involvement } \\
\text { in the } \\
\text { process }\end{array}$ & & ID & $\begin{array}{l}\text { Involvement } \\
\text { in the } \\
\text { process }\end{array}$ \\
\hline \multirow[t]{10}{*}{$\begin{array}{l}\text { Govern-mental } \\
\text { Autho-rities }\end{array}$} & $\begin{array}{l}\text { Ministry of } \\
\text { Health }\end{array}$ & MS & Int33" & Direct & vws & Int19 & Direct \\
\hline & Health & DGS & Int09" & Direct & & & \\
\hline & directorate & & Int15" & Direct & & & \\
\hline & Health Council & HCSP/CTV & Int10 & Direct & GR & Int18 & Direct \\
\hline & & & Int08 & Direct & & Int21 & Direct \\
\hline & & & Int12 & Direct & & Int23 & Direct \\
\hline & & $\mathrm{HAS} / \mathrm{CT}$ & Int06 & Indirect & & & \\
\hline & $\begin{array}{l}\text { Medicines } \\
\text { Evaluation } \\
\text { Board }\end{array}$ & ANSM & - & Indirect & CBG & Int27 & Indirect \\
\hline & $\begin{array}{l}\text { Healthcare } \\
\text { insurance } \\
\text { board }\end{array}$ & CNAMTS & - & Indirect & CVZ & - & Indirect \\
\hline & $\begin{array}{l}\text { Medicines } \\
\text { Regula- } \\
\text { tory/Financial } \\
\text { Board }\end{array}$ & CEPS & Int13 & Indirect & RIVM/DVP & Int $28^{* *}$ & Indirect \\
\hline \multirow[t]{10}{*}{$\begin{array}{l}\text { Research } \\
\text { institu-tions }\end{array}$} & $\begin{array}{l}\text { Influenza } \\
\text { surveillance }\end{array}$ & GROG & Int02 & Indirect & NIVEL & Int16 & Indirect \\
\hline & networks & & Int03 & Indirect & & Int26 & Indirect \\
\hline & $\begin{array}{l}\text { National } \\
\text { Influenza } \\
\text { Centre }\end{array}$ & CNR Paris & Int05 & Indirect & NIC & Int32 & Indirect \\
\hline & сетाtте & CNR Lyon & Int01 & Indirect & Rotterdam & & \\
\hline & Institute of & InVs & Int11 & Direct & RIVM & Int20 & Direct \\
\hline & Public Health & & & & & Int22 & Direct \\
\hline & Research \& & & & & & Int24 & Direct \\
\hline & Monitoring & & & & & Int29 & Direct \\
\hline & & & & & & Int30 & Direct \\
\hline & & & & & & Int31 & Direct \\
\hline Associ-ations & $\begin{array}{l}\text { Society of } \\
\text { experts/ } \\
\text { College of GPs }\end{array}$ & SPILF & Int07 & Indirect & NHG & Int25 & Indirect \\
\hline \multirow{2}{*}{\multicolumn{2}{|c|}{$\begin{array}{l}\text { Vaccine } \\
\text { manufacturers }\end{array}$}} & GSK & Int04" & Indirect & Abbott & Int17 & Indirect \\
\hline & & SPMSD & Int14 & Indirect & & & \\
\hline \multicolumn{2}{|c|}{ Total number of interviews conducted } & & 16 & & 17 & & \\
\hline
\end{tabular}

Key: ID-interview identification; MS-Ministère des Affaires sociales et de la Santé; CNAMTS-Caisse nationale de l'assurance maladie des travailleurs salaries; CEPS-Comité Économique des Produits de Santé; DGS-Direction Générale de la Santé; ANSM-Agence National de Sécurité du Médicament; HCSP-Haut Conseil de Santé Publique; CTV-Comité technique des vaccinations; HAS-Haute Autorité de Santé; CT - Commission de la Transparence; SPILF- Société de Pathologie Infectieuse de Langue Française; InVS - Institut de Veille Sanitaire; GROG - Groupes Régionaux d'Observation de la Grippe; CNR - Centre National de Référence; VWS - Ministry of Health, Welfare and Sport; GR - Health Council; CVZ - National Health Care Institute; CBG - Medicines Evaluation Board; RIVM - National Institute of Public Health and Environment; NIVEL- Netherlands institute for health services research; NIC-National Influenza Centre; NHG-Dutch College of General Practitioners; DVP-National service for vaccine provision of prevention programs; GSK-GlaxoSmithKline; SPMSD- Sanofi Pasteur Vaccines.

- No longer at the position during the interview.

* Face-to-face interview conducted with more than one person, as suggested by the invited expert. 
Silva, M.L., Perrier, L., Paget, W.J., Mosnier, A., Buthion, V., Cohen, J.M., Späth, H.M. Influenza/ vaccination policy-making processes in France and The Netherlands: framework and determinants. Health Policy: 2016, 120(3), 293-305
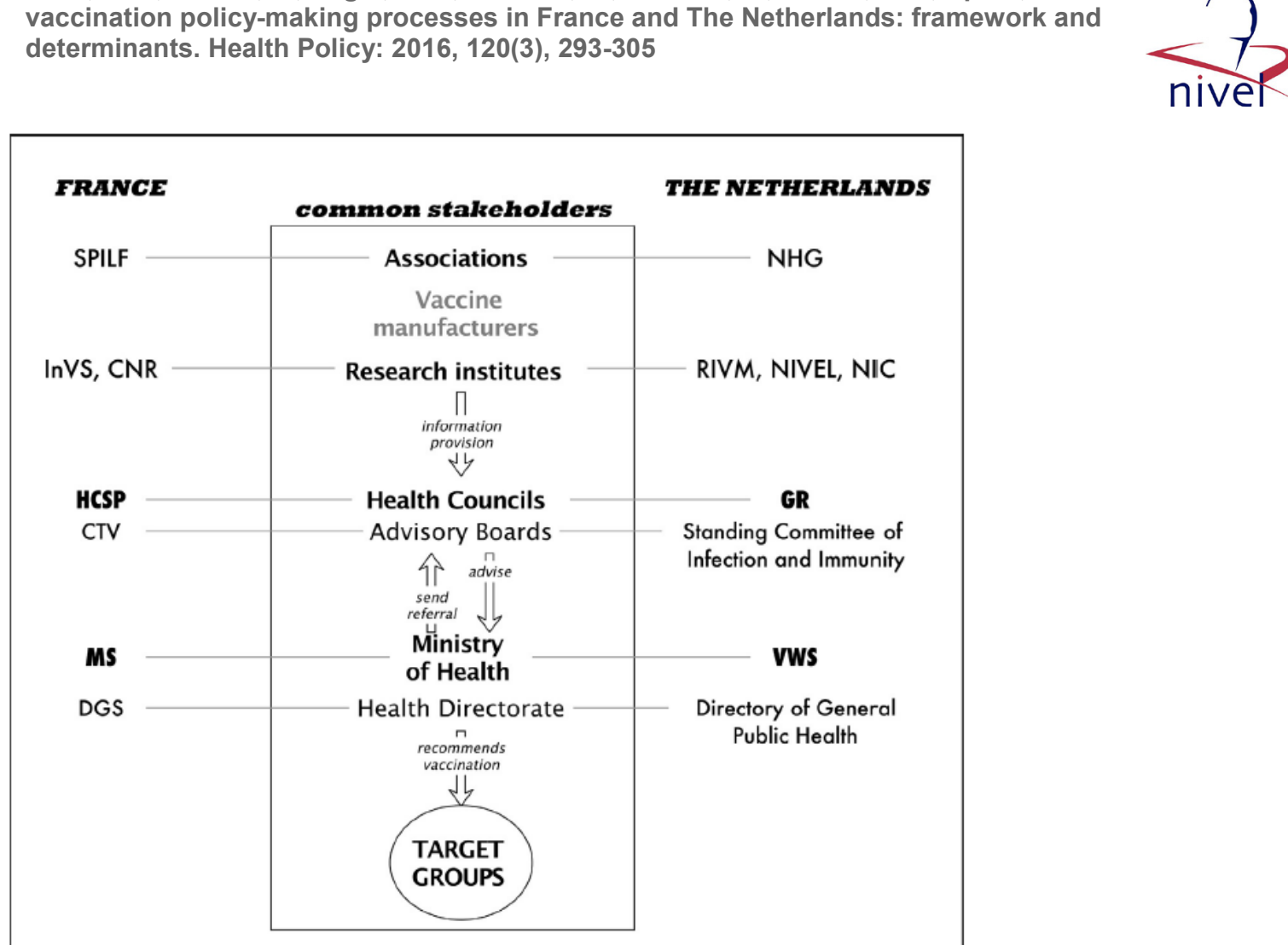

Key for France: MS = Ministry of Social Affairs, Health and Women rights; DGS = Health Directorate General; HCSP = High Council for Public Health; CTV = Technical Vaccination Committee; InVS = Institute for Public Health Surveillance; $\mathrm{CNR}=$ National Reference Centre; SPILF $=$ French Infectious Diseases Society

Key for The Netherlands: VWS = Ministry of Health, Welfare and Sport; GR = Health Council; RIVM = National Institute of Public Health and Environment; NIVEL = Netherlands Institute for Health Services Research; NIC = National Influenza Centre; NHG = Dutch College of General Practitioners

Fig. 1. The decision-making process of influenza vaccination recommendations and examples of the stakeholders in France and The Netherlands. 
Silva, M.L., Perrier, L., Paget, W.J., Mosnier, A., Buthion, V., Cohen, J.M., Späth, H.M. Influenza vaccination policy-making processes in France and The Netherlands: framework and determinants. Health Policy: 2016, 120(3), 293-305
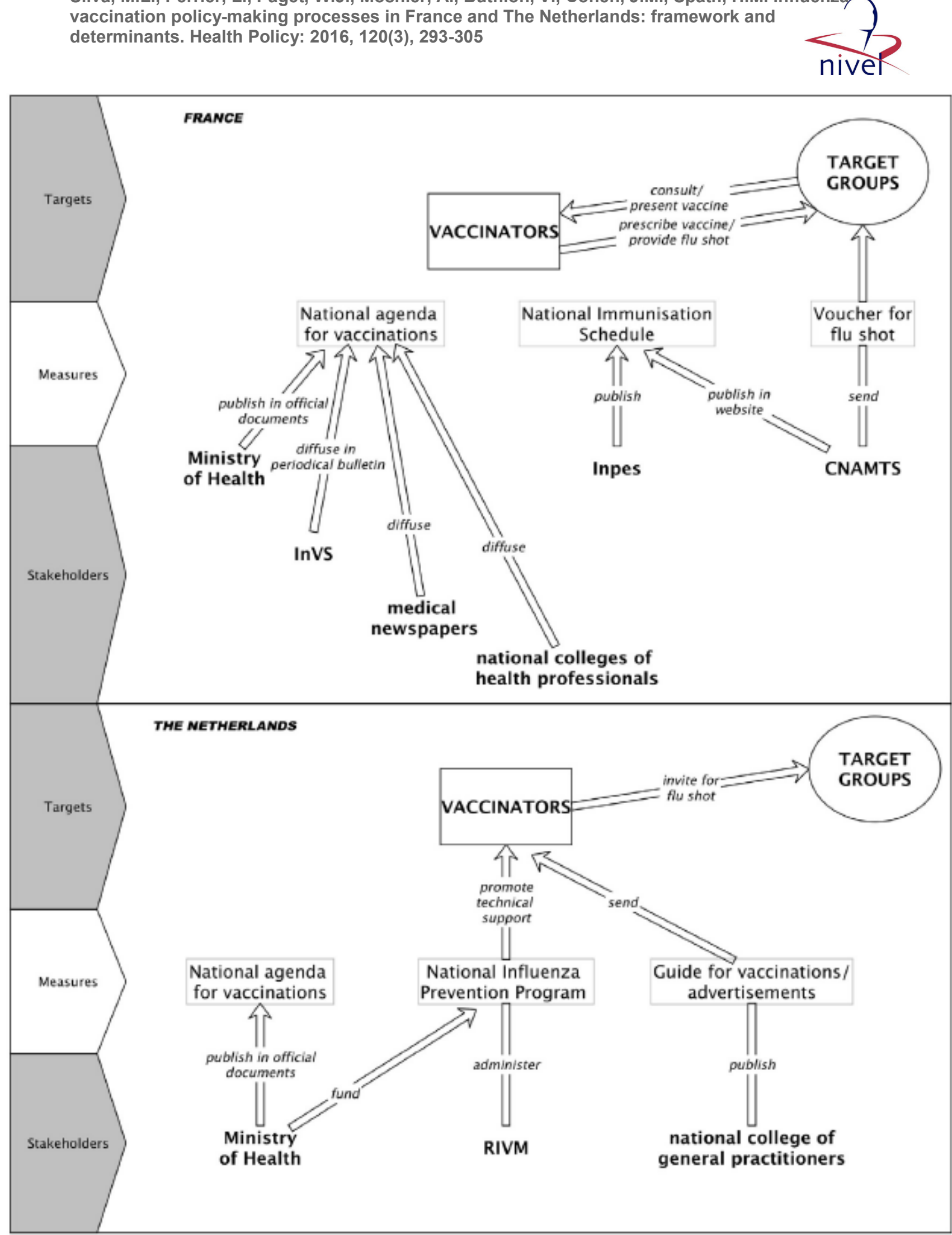

Key: InVS = French Institute for Public Health Surveillance; Inpes = French Institute for Prevention and Health Education; CNAMTS = National Health Insurance Fund; RIVM = National Institute for Public Health and the Environment

Fig. 2. Schematic of the implementation of influenza vaccination recommendations in France and The Netherlands. 
Silva, M.L., Perrier, L., Paget, W.J., Mosnier, A., Buthion, V., Cohen, J.M., Späth, H.M. Influenza vaccination policy-making processes in France and The Netherlands: framework and determinants. Health Policy: 2016, 120(3), 293-305
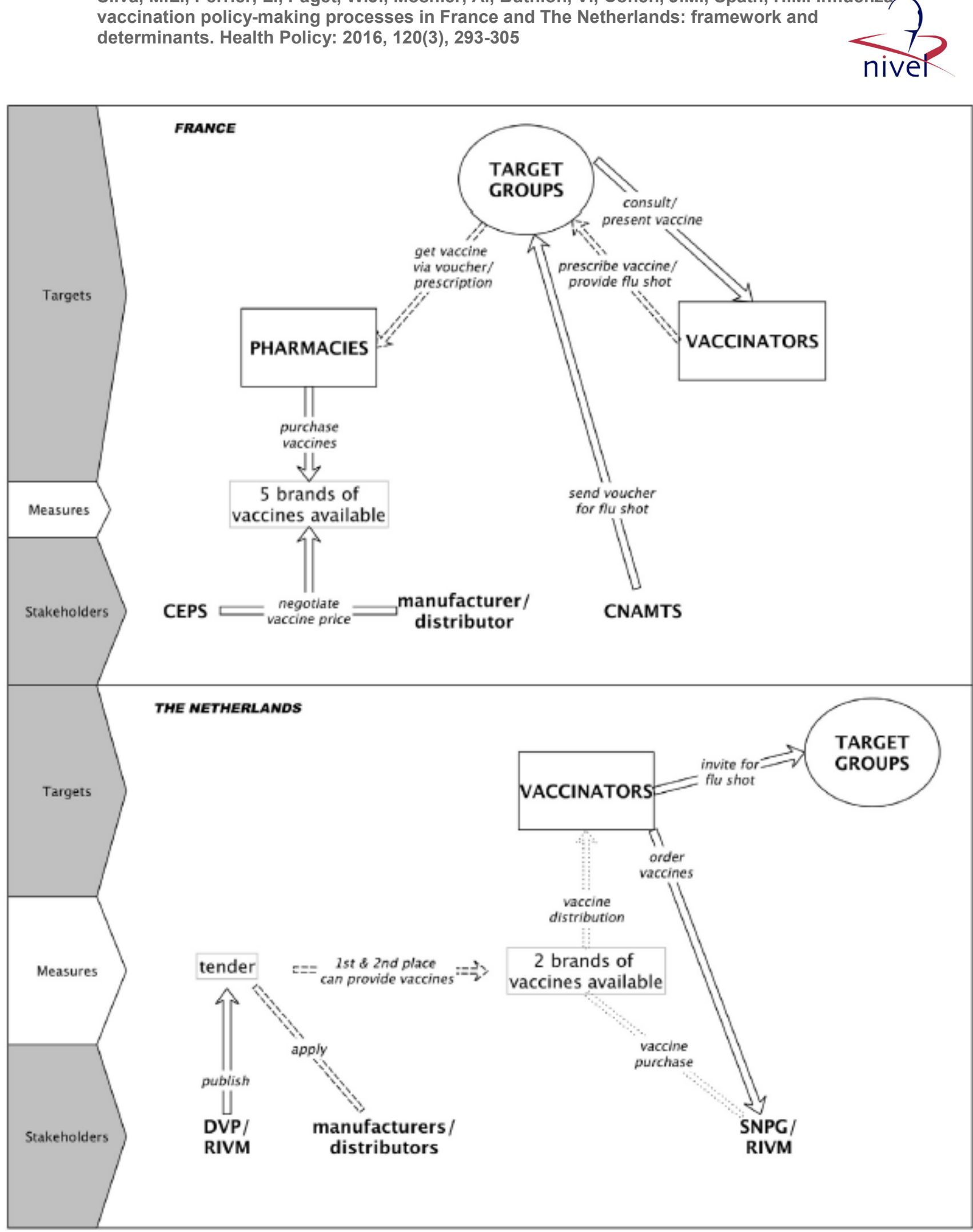

Key: CEPS $=$ Economic Committee for Medicinal Products, linked to the Ministry of Health and Ministry of Economy; CNAMTS = National Health Insurance Fund; DVP = National Service for Vaccine Provision of Prevention Programs; SNPG = National Influenza Prevention Program; RIVM = National Institute for Public Health and the Environment

Fig. 3. Schematic of the funding of influenza vaccinations in France and The Netherlands, 
Box 1: Strategy for online database searches, keywords (English, French, and Dutch), and main sources of material obtained for France and The Netherlands

\begin{tabular}{|c|c|c|}
\hline \multicolumn{3}{|c|}{$\begin{array}{l}\text { Keywords (similar for both countries): } \\
\text { health, Gross Domestic Product (GDP), indicators, economy }\end{array}$} \\
\hline \multicolumn{3}{|c|}{$\begin{array}{l}\text { Websites (similar for both countries): } \\
\text { OECD (http://data.oecd.org/gdp/gross-domestic-product-gdp.htm), } \\
\text { WHO (http://data.euro.who.int/healthatlas/CoreIndicatorAP/corenotes.htm) }\end{array}$} \\
\hline \multicolumn{3}{|l|}{ (ii) health systems } \\
\hline \multicolumn{3}{|c|}{$\begin{array}{l}\text { Websites (similar for both countries): } \\
\text { European Observatory on Health Systems and Policies } \\
\text { (http://www.euro.who.int/en/about-us/partners/observatory) }\end{array}$} \\
\hline \multicolumn{3}{|c|}{ (iii) influenza vaccination policies and (iv) stakeholders involved in policies * } \\
\hline Keywords: & $\begin{array}{l}\text { Grippe, vaccination, vaccin, } \\
\text { remboursement, stratégie vaccinale, } \\
\text { recommandation, avis, rapport, } \\
\text { conseil }\end{array}$ & $\begin{array}{l}\text { Griep, influenza, vaccinatie, vaccin, vergoeden, } \\
\text { vaccinatiestrategie, rapport, advise, recommandatie }\end{array}$ \\
\hline \multicolumn{3}{|l|}{ Websites: } \\
\hline Ministries of health & http://www.sante.gouv.fr & http://www.rijksoverheid.nl/ministeries/vws \\
\hline Governmental & http://www.hcsp.fr/explore.cgi & http://www.gezondheidsraad.nl \\
\hline authorities & http://www.has-sante.fr & http://www.cbg-meb.nl/cbg/nl \\
\hline & http://ansm.sante.fr & http://www.zorginstituutnederland.nl \\
\hline & http://www.ameli.fr & http://www.rivm.nl \\
\hline Laboratories, & http://grog.org & http://www.nivel.nl \\
\hline Surveillance networks & http://www.invs.sante.fr & http://www.snpg.nl \\
\hline Associations & $\begin{array}{l}\text { http://www.infectiologie.com } \\
\text { http://www.grippe-geig.com }\end{array}$ & https://www.nhg.org \\
\hline
\end{tabular}

*Dutch websites were automatically translated to English using the Chrome ${ }^{\circledR}$ browser 
ANNEXE 1: INDIVIDUAL SEMI-STRUCTURED INTERVIEW GUIDE; ENGLISH VERSION FOR THE NETHERLANDS

Before starting the interview, the interviewer will briefly develop the following points:

- Personal and thesis presentation

- $\quad$ State that the interview will be recorded

Opening point

1) What do you think about the actual seasonal influenza vaccination strategy in The Netherlands?

The experts and their relationships

1) In this field, what is your expertise?

a. Currently and in the past three years, for which institutions have you worked?

2) Have you been involved (directly or indirectly) in meetings regarding influenza vaccination or vaccine policy (recommendations, campaigns, reimbursements)? When, which one?

a. In what level did you participate in this meeting?

b. Are the experts the same?

3) What do you think about the relationship among experts who participated with you in this meeting?

a. Were all "flu expertise" represented? What were the missing skills, according to you?

b. Which kind of foreign experts participated? From which institution?

4) Could you please talk about the degree of influence among the experts?

a. Do you think it is most related to their institution or their skills?

5) What is the role of the ECDC and the WHO in the policy-making process?

The policy-making process

1) Could you please give more details about the flow or the development of those meetings?

a. Is there any written or oral procedure?

b. How are the different opinions managed and solved?

2) Could you please give further details about the interrelations regarding the following institutions (related to influenza vaccination/vaccines):
a. GR: Health Council
b. CBG: Medicines Evaluation Board
c. CIBG: Central Information for Healthcare Professions
d. CVZ and IGZ: Healthcare Insurance Board and Healthcare Inspectorate
e. RIVM Cib/CvB: Centre for Infectious Disease Control/Centre for Population Screening

Closing points

1) What works well in the process? What could be improved? What possible changes are in progress?

2) Is there any additional information or comments would you like to share?

3) Can you recommend another person I should talk to get a perspective that complements yours or that is completely different? 


\section{ANNEXE 2: MAIN DOCUMENTS ANALYSED DURING THE QUALITATIVE RESEARCH (IN ALPHABETICAL ORDER)}

- Bégué P. [Consequences of opposition to vaccination in France and Europe. How to maintain effective vaccine coverage in 2010?]. Bull Acad Natl Med. 2010 May;194(4-5):719-32; discussion 732.

- Bégué P. [Vaccine refusal and implications for public health in 2012]. Bull Acad Natl Med. 2012 Mar;196(3):60317; discussion 617-20.

- Chevreul K, Durand-Zaleski I, Bahrami SB, Hernández-Quevedo C, Mladovsky P. France: Health system review. Health Syst Transit. 2010;12(6):1-291, xxi - xxii.

- Coudin É, Samson A-L, Pla A. Régulation des tarifs et comportments d'offre de soins des généralistes: les leçons de l'encadrement du secteur 2. 2015 [cited 2015 Aug 17]; Available from: http://basepub.dauphine.fr/handle/123456789/14552

- Donker GA. NIVEL Primary Care Database - Sentinel Practices 2013 [Internet]. Netherlands institute for health services research; 2015. Available from: http://www.nivel.nl/en/nivel-primary-care-database-SentinelPractices $\% 20$

- $\quad$ E.A. Stolk, F.F.H. Rutten. The health basket in the Netherlands. A contribution to Work Package II of the EU funded research project "HealthBASKET": Description of benefits, entitlements, actors and decision making processes in the Dutch health care sector. Erasmus MC, Rotterdam. April 2005.

- Floret D, Deutsch P. The French Technical Vaccination Committee (CTV). Vaccine. 2010 Apr 19;28, Supplement 1:A42-7.

- Floret D. Vaccinations : élaboration des recommandations et de leur évolution en France. Annales Pharmaceutiques Françaises. 2009 May;67(3):219-23.

- French PE. Enhancing the Legitimacy of Local Government Pandemic Influenza Planning through Transparency and Public Engagement. Public Administration Review. 2011;71(2):253-64.

- Garrido MV, Kristensen FB, Nielsen CP, Busse R. Health technology assessment and health policy-making in Europe. Current status, challenges and potential [Internet]. European Observatory on Health Systems and Policies; 2008 [cited 2013 Jun 26]. 181 p. Available from: http://www.euro.who.int/en/who-weare/partners/observatory/studies/health-technology-assessment-and-health-policy-making-in-europe.-currentstatus,-challenges-and-potential

- Gautier A. Baromètre santé médecins généralistes 2009 [Internet]. Saint-Denis: Inpes; 2011 [cited 2015 Jul 31] p. 266. Available from: http://www.inpes.sante.fr/Barometres/Barometre-sante-medecins-generalistes-2009/index.asp

- Hak E, Buskens E, van Essen GA, de Bakker DH, Grobbee DE, Tacken MAJB, et al. Clinical effectiveness of influenza vaccination in persons younger than 65 years with high-risk medical conditions: the PRISMA study. Arch Intern Med. 2005 Feb 14;165(3):274-80.

- HAS. Haute Autorité de Santé - Transparency Committee Opinion - Oseltamivir Phosphate. Medical, Economic and Public Health Assessment Division; 2008. 14 p.

- Henry S, Manuguerra J-C, Escourolle D, Bessette D, Camus D, Houssin D. [National plan for the prevention and control "influenza pandemic"]. Rev Prat. 2008 Oct 15;58(15):1687-93.

- Houweling H, Verweij M, Ruitenberg EJ. Criteria for inclusion of vaccinations in public programmes. Vaccine. 2010 Apr 9;28(17):2924-31.

- Houweling H, Wittevrongel CFW, Verweij M, Ruitenberg EJ. Public vaccination programmes against hepatitis B in The Netherlands: Assessing whether a targeted or a universal approach is appropriate. Vaccine. 2010 Nov 16;28(49):7723-30.

- $\quad$ INVS I de veille sanitaire. Surveillance épidémiologique et virologique de la grippe en France, saison 2010-2011. BEH. 2011 Nov 10;37-38:394-8.

- INVS. Le Calendrier des vaccinations et les recommandations vaccinales 2011 selon l'avis du Haut Conseil de la santé publique. 2011.

- Joseph J-P, Staffolani F, Kinouani S, Broussy S, Picat M-Q, Senand B, et al. [Seasonal influenza vaccination coverage of general practitioners and their patients. Practice survey of French general practitioners after vaccination campaign 2011-2012.]. Rev Epidemiol Sante Publique. 2014 Oct 16;62(5):291-6.

- Kirschner K, Braspenning J, Akkermans RP, Jacobs JEA, Grol R. Assessment of a pay-for-performance program in primary care designed by target users. Fam Pract. 2013 Apr;30(2):161-71.

- $\quad$ Labro MT, Etiemble J. [The strategy against influenza]. Rev Prat. 2010;60(1):81-92.

- Manuguerra J-C, Mosnier A, Autran B, Fleury M, Veyssier P, Patey O, et al. [The French Committee for the prevention and control of influenza and the 2009 influenza pandemic: Lessons learnt]. Presse Med. 2012 Sep;41(9 Pt 1):783-92. 
- Matysiak-Klose D, Ahmed F, Duclos P, Falck-Ytter Y, Forland F, Houweling H, et al. Report on the 1st international workshop on procedures for the development of evidence-based vaccination recommendations, Berlin, Germany, 22-23 November 2010. Vaccine. 2012 Mar 23;30(14):2399-404.

- Mereckiene J, Cotter S, Nicoll A, Lopalco P, Noori T, Weber JT, et al. Seasonal influenza immunisation in Europe. Overview of recommendations and vaccination coverage for three seasons: pre-pandemic (2008/09), pandemic (2009/10) and post-pandemic (2010/11). 2014 [cited 2014 Jul 5]; Available from: http://edoc.rki.de/docviews/abstract.php?lang=ger\&id=3541

- Ministère de la Santé. Campagne de vaccination contre la grippe saisonnière 2014-2015. 2014.

- O'Flanagan D, Cotter S, Mereckiene J. Seasonal influenza vaccination in EU/EEA, influenza season 2011 - 12. Italy: The European Centre for Disease Prevention and Control (ECDC); 2013 p. 67. Report No.: September 2012- February 2013.

- $\quad$ Schäfer W, Kroneman M, Boerma W, van den Berg M, Westert GP, Devillé W, et al. The Netherlands: Health system review. Health Syst Transit. 2010;12(1):1-229, xxi - xxii.

- Tabuteau D. L'expert et la décision en santé publique. Les Tribunes de la santé. 2010 Jun 28;n² 27(2):33-48.

- Tacken MAJB, Jansen B, Mulder J, Tiersma W, Braspenning JCC. Monitoring Vaccination rate Dutch National Influenza Prevention Program 2013 [Internet]. 2014 [cited 2015 Jan 8]. Available from: http://www.rivm.nl/dsresource?objectid=rivmp:260408\&type=org\&disposition=inline

- Timmermans J. Seasonal Influenza Programme, The Netherlands. National Programme on Influenza Protection. RIVM, 2015.

- Tuppin P, Samson S, Weill A, Ricordeau P, Allemand H. Seasonal influenza vaccination coverage in France during two influenza seasons (2007 and 2008) and during a context of pandemic influenza A(H1N1) in 2009. Vaccine. 2011;29(28):4632-7.

- Verweij MF, Houweling H. What is the responsibility of national government with respect to vaccination? Vaccine. 2014 Dec 12;32(52):7163-6.

- Vos HMM, Adan IMA, Schellevis FG, Lagro-Janssen ALM. Prevention in primary care: facilitators and barriers to transform prevention from a random coincidence to a systematic approach. J Eval Clin Pract. 2014 Jun;20(3):20815.

- Vrieze HA, van Haaren KMA, Drenthen AJM, van Schaik B, Dayan M. NHG/SNPG-Handleiding - De organisatie en uitvoering van de influenzavaccinatie in de huisartsenpraktijk [Internet]. Nederlands Huisartsen Genootschap; 2014. Available from: http://snpg.nl/producten/2014/NHG-SNPG-Handleiding-Influenza-oktober-2014.pdf

- VWS. Subsidieregeling publieke gezondheid [Internet]. Wet- en regelgeving. 2014 [cited 2014 Dec 18]. Available from: http://wetten.overheid.nl/BWBR0018743/geldigheidsdatum_10-12-2014/

- WHO/Europe. Core Health Indicators in the WHO European Region 2013 [Internet]. 2013 [cited 2014 Aug 26]. Available from: http://www.euro.who.int/en/data-and-evidence/core-health-indicators-in-the-who-european-region2013.-special-focus-noncommunicable-diseases 